Gut, 1960, 1, 67.

\title{
DIAGNOSTIC SIGNIFICANCE OF D.XYLOSE EXCRETION TEST
}

\author{
BY \\ D. FOWLER and W. T. COOKE \\ From the General Hospital, Birmingham
}

This paper assesses the use of d.xylose as a test of function of the small intestine. In general d.xylose excretion is associated with disturbance of the intestinal wall of the upper jejunum. Low readings are found with adult coeliac disease but rarely with regional enteritis.

The excretion of d.xylose in the urine after the ingestion of a known quantity is used as a test of intestinal absorption. In particular, its use in conditions associated with steatorrhoea has been reported by Fourman (1948), Brien, Turner, Watson, and Geddes (1952), Gardner and Perez Santiago (1956), Benson, Culver, Ragland, Jones, Drummey, and Bougas (1957), Finlay and Wightman (1958), and Butterworth, Perez Santiago, Martinez-de Jesus, and Santini (1959). The purpose of this paper is to assess this test as a routine diagnostic measure in the investigation of disorders of the small intestine.

\section{Material AND Methods}

d.Xylose, $25 \mathrm{~g}$. in $250 \mathrm{ml}$. of water, was administered to patients and normal subjects in the fasting state. A further $250 \mathrm{ml}$. of water was taken at once and again one and two hours later, i.e., approximately 1 litre of water in all. The bladder was emptied voluntarily at the beginning of the test and all urine passed in the five hours after the ingestion of d.xylose was collected and kept in a refrigerator until analysed. Storage in the cold for periods of at least a week made no difference to the results. Though the majority of patients were confined to bed during the performance of the test, the normal subjects and out-patients were ambulant.

d.Xylose was determined by the method of Roe and Rice (1948). In a number of patients, the folic acid excretion test (Cox, Meynell, Cooke, and Gaddie, 1958), jejunal biopsy (Crosby and Kugler, 1957), haematological survey, intestinal radiology, and determination of faecal fat were performed.

Control data were provided by 43 normal subjects, 31 medical students and hospital staff (18 men and 13 women aged 20-50), and 12 hospital patients without anaemia or intestinal disorder (four aged 33-62 and eight aged 69-98 years). One hundred and thirty-six patients were also studied, suffering from various disorders as indicated in Table I and detailed further in the results of the investigation.

\section{RESULTS}

The results in the various groups of subjects are summarized in Table I.

FORTY-THREE NORMAL CONTROLS.-Inspection of the results showed that the eight subjects aged 65 and over had a mean d.xylose excretion of $2.85 \mathrm{~g}$. (S.E. 0.10) whereas 35 subjects under the age of 65 years had a mean excretion of $7 \cdot 24$ g. (S.E. 0.27) in

TABLE I

FIVE-HOUR URINARY EXCRETION OF D.XYLOSE IN 179 SUBBJECTS AFTER ORAL INGESTION OF 25 G. D.XYLOSE

\begin{tabular}{|c|c|c|c|c|c|c|c|c|}
\hline \multirow[b]{2}{*}{ Diagnosis } & \multicolumn{4}{|c|}{ Under 65 Years } & \multicolumn{4}{|c|}{ Over 65 Years } \\
\hline & $\begin{array}{l}\text { No. of } \\
\text { Subjects }\end{array}$ & Range (g.) & Mean (g.) & S.E. & $\begin{array}{l}\text { No. of } \\
\text { Subjects }\end{array}$ & Range (g.) & Mean (g.) & S.E. \\
\hline
\end{tabular}


five hours. The mean urine volume, $319 \mathrm{ml}$., was much less than the mean urine volume, $667 \mathrm{ml}$., of the larger number of younger subjects. Partial correlation between xylose and volume in the younger group of 35 subjects $(R=+0.27)$ and the whole group of 43 subjects $(R=+0.26)$ was not significant. On the other hand, partial correlation between age and xylose in the younger group was not significant $(R=-0.22)$ but was significant in the whole group of 43 subjects $(R=-0.65)$ at the $1 \%$ level. The lower limit of normal was, therefore, set at $4 \cdot 2 \mathrm{~g}$. in five hours, i.e., 7.24 - 2 S.D., and lower results in any patient aged 65 and over were not regarded as being indicative of any abnormality.

Twenty-two Patients with Adult Coeliac DISEASE.-Inspection of the data indicated that neither age nor low urine volumes were responsible for the poor excretion of d.xylose in this group. Two patients excreted 5.3 and $4.9 \mathrm{~g}$. respectively. One of these had been controlled clinically by a gluten-free diet for five years though he still had some excess of fat in his faeces. The second patient, a girl aged 19, had had severe coeliac disease and though not on a gluten-free diet was clinically well. Both had abnormal folic acid excretion tests and characteristically abnormal jejunal biopsies. Though other patients were clinically well either on a gluten-free diet or steroid therapy, none showed normal xylose excretion or normal folic acid excretion.

Thirteen Patients with Pancreatitis.-There was one abnormal result, $3.4 \mathrm{~g}$., in a 68 -year-old woman. In the remaining patients, d.xylose excretion was normal, ranging from 4.2 to $10.7 \mathrm{~g}$. The 35-year-old patient with the borderline result of $4.2 \mathrm{~g}$. had steatorrhoea responding to therapy with pancreatin, repeated upper respiratory and lung infections, bronchiectasis, and abnormalities in the $\gamma$-globulin fraction of the serum proteins, agglutinins to B group being almost absent and a fast moving component of the $\gamma$ fraction deficient on immune electrophoresis.

Ten Patients with Pernicious Anaemia.Abnormal results were encountered in five. Of these, four were aged $61,76,76$, and 79 years, and a 35 -year-old woman before therapy, who fulfilled acceptable criteria for the diagnosis of pernicious anaemia, namely, histamine-fast achlorhydria, megaloblastic bone marrow, normal faecal fat excretion, low serum B.12, normal haematological response to B.12, and a normal jejunal biopsy. She did, however, show an unusual amino-aciduria for which we have no adequate explanation at present. All patients had a normal faecal fat excretion. Of the five patients who had normal results, four had received B.12 therapy and one had had a folic acid excretion test. The three oldest patients with abnormal results had also received B.12 therapy but neither the man aged 61 nor the woman aged 35 had done so.

Thirteen Patients With Post-gastrectomy StATES.-The only abnormal results were encountered in three patients who were over 65 years of age.

ThiRTeen Patients with Ulcerative Colitis AND FOUR WITH ENTEROCOLITIS.-These gave normal results. All the patients were aged less than 65 .

Nine Patients with Cirrhosis of Liver.-No abnormal results were encountered though one patient was more than 65 years old.

Seventeen Patients with Regional Enteritis. -Only two low results were encountered. One, $3.7 \mathrm{~g}$., was in a 35 -year-old man with extensive intestinal involvement and a high jejuno-ileal fistula. The urine volume was, however, low $(97 \mathrm{ml}$.) so that a small error in collection might have accounted for this abnormal result. The other, $3.6 \mathrm{~g}$., was in a 23-year-old woman with jejunal involvement radiologically demonstrated.

Seven Patients with Megaloblastic Anaemia of Pregnancy.-Two abnormal results were obtained. One patient aged 20 had previously been diagnosed as "idiopathic steatorrhoea" and was taking folic acid when first seen. Faecal fat determinations, however, during pregnancy and again in the puerperium were normal. A folic acid excretion test was abnormal. In the second, no steatorrhoea was present and there was no history of previous illness. On the other hand, one normal result (4.8 g.) was encountered in a 23 -year-old woman in her second pregnancy in whom steatorrhoea was present.

Twenty-eight Patients with Miscellaneous Disorders.-Five patients were investigated for diarrhoea for which no organic cause could be identified. In each, faecal fat excretion, intestinal radiology, a full haematological survey, urine chromatography, folic acid excretion, glucose tolerance, and xylose excretion tests were all normal. Two patients with macrocytic anaemia, steatorrhoea, and extensive short circuits of the small intestine excreted 5.8 and $8.4 \mathrm{~g}$. respectively even though the first patient was 67 years of age. One patient, with an argentaffinoma tumour of the small intestine and extensive deposits in the mesentery, excreted $5.8 \mathrm{~g}$. One patient with an ileostomy excreted $5.8 \mathrm{~g}$. 
and one patient with pancreatitis, agammaglobulinaemia, and steatorrhoea $5 \cdot 3 \mathrm{~g}$. Two patients with extensive diverticula of the small intestine involving the jejunum, macrocytic anaemia, and steatorrhoea excreted 3.3 and $2.9 \mathrm{~g}$. respectively. One patient aged 54, with a chronic atrophic fibrosing process of the jejunum, excreted $3 \cdot 2 \mathrm{~g}$. Another woman aged 54, with a history of 20 years of persistent hypochromic anaemia possibly due to hiatus hernia and oesophagitis, normal jejunal biopsy, and steatorrhoea, only excreted $3 \cdot 8 \mathrm{~g}$.

\section{Discussion}

d.Xylose is absorbed in the upper small intestine (McCance and Madders, 1930) and in rats over $90 \%$ of the ingested dose has disappeared from the intestines in one hour (Butterworth et al., 1959). The bulk of evidence suggests that phosphorylation is involved in the absorptive mechanism of xylose (Hele, 1953; Ota and Shibata, 1954). Approximately 40 to $45 \%$ of an ingested dose of d.xylose in man is excreted in the urine in 24 hours (McCance and Madders, 1930; Wyngaarden, Segal, and Foley, 1957; Butterworth et al., 1959). d.Xylose that is metabolized is incorporated into liver glycogen (Hiatt, 1957) whilst Wyngaarden et al. found that $13.5 \%$ of a dose of d.xylose I.C..$^{14}$ given intravenously in man is excreted as carbon dioxide.

As Finlay and Wightman (1958) hinted, d.xylose excretion did appear to diminish in the older age groups and we found it necessary to discount abnormally low results in patients 65 years and older. As was shown by McCance and Madders (1930), d.xylose excretion was independent of urine volume in both the young and old subjects in our control series.

There is some variation in the reported amounts of d.xylose excreted by normal subjects in five hours. The mean excretion varies from 5.6 to $6.7 \mathrm{~g}$. Using the limit set by the mean less twice the standard deviation, the lowest limit of normal is $2.9 \mathrm{~g}$. reported by Butterworth et al. in 100 Puerto Rican subjects aged 18 to 26 and 14 hospital laboratory staff aged 20 to 50 years, the largest group that has been studied. Our findings gave a mean excretion much higher than others. The reason is not immediately apparent but our lower limit is set at the same level as that used by Benson et al. This variation of the reported normal excretion in five hours does impose some restriction on the random use of the test but less than $3 \mathrm{~g}$. can safely be assumed to be abnormal.

The blood xylose levels were not investigated in our patients for two reasons, first to keep the test as simple as possible, and secondly, to avoid the inherent difficulty of assessing any absorption curve.
However, Benson and his colleagues have suggested that blood xylose levels should be estimated two hours after the test dose. The finding of normal levels and low urinary excretion indicates, in their view, impaired renal excretion. In those patients in whom we were unable satisfactorily to explain low urinary excretions, routine kidney function tests, including creatinine clearance, did not appear to account for our findings.

The high incidence of low results in the control subjects and patients over the age of 65 compelled us to place no significance on such low values. Thus, in pernicious anaemia low values were found in four patients aged 61 to 79 . Helmer and Fouts (1937) were unable to demonstrate any consistent abnormality in excretion of d.xylose in 48 patients with pernicious anaemia. Of these, 30 excreted less than $4.2 \mathrm{~g}$.; of these 30 patients, 19 had a urea clearance of less than $70 \%$ and of these 10 were over 60 and the age of one was not known. Of the remaining 11 patients, five were over 60 . There remained six who had a low d.xylose excretion for which no reason was apparent. It is possible that some may have had intestinal disorders had modern diagnostic procedures been used. We have concluded that the finding of a five-hour d.xylose excretion of less than $4.2 \mathrm{~g}$. in a patient under 60 makes the diagnosis of pernicious anaemia uncertain.

Benson et al. (1957) found that seven out of 13 of their patients who had undergone partial gastrectomy had low results; two of these were aged 65 and 67, though three patients aged 61 all had normal results. In our patients, the only two abnormal results were in elderly patients aged 65 and 71 . We consider that the test can offer little additional information in this group of patients. In regional enteritis, the only two patients to have some involvement of the jejunum had a low excretion, though in one this finding could have been attributed also to the low urine volume. These results contrast with those reported by Benson $e t$ al. who reported that two out of four patients with regional ileitis had a low excretion.

Both Benson et al. (1957) and Finlay and Wightman (1958) found that some patients with adult coeliac disease had normal d.xylose excretion. In our two patients there seems little doubt as to the correctness of the diagnosis, according to presentday criteria. It has also been reported that improvement in xylose excretion takes place with clinical remission (Finlay and Wightman, 1958) though in our patients this was not significant in the few patients in whom the tests have been repeated or in those who had been under treatment for a long time. 
The presence of severe liver dysfunction made no difference to the test for the results in our patients with cirrhosis were normally distributed around our mean normal excretion. - Butterworth et al. (1959) showed that d.xylose was excreted in significantly greater quantities if the liver was by-passed and Wyngaarden et al. noted that d.xylose was removed more slowly from the blood in patients with cirrhosis. Hence though the five-hour excretions are within the normal range the results do not necessarily imply that the absorption mechanism is normal.

It is evident both from our results and those recorded in the literature that d.xylose excretion is normal in pancreatitis with steatorrhoea. Gardner and Perez Santiago (1956) have reported on the usefulness of this test in tropical sprue. They found d.xylose excretion consistently low in the untreated patients and no significant difference in the results of a group of patients already on treatment, many for months or years. Butterworth et al. (1959) in a more extended study did show an improvement in the mean excretion in treated patients with sprue, the mean excretion of 49 untreated patients being $1.4 \mathrm{~g}$. (S.D. 0.7) and of 28 treated sprue patients $3.5 \mathrm{~g}$. (S.D. 1.3). Only one patient with tropical sprue has been investigated by us. In her the excretion was low, $1.5 \mathrm{~g}$.

As a result of our experiences in the use of this test we believe that it provides useful information in patients with a macrocytic anaemia other than those in whom previous surgery on the stomach or small intestine has been carried out. Certainly the finding of low xylose excretion in a patient with "pernicious anaemia" should necessitate the fullest investigation before such a diagnosis can be considered substantiated. Similarly the finding of a normal d.xylose excretion test in a patient with "adult coeliac disease" should lead to a careful review of the diagnosis. The test is also of use in excluding chronic pancreatitis as a cause of diarrhoea for a low excretion is improbable in pancreatic disorders.

In general, d.xylose excretion is associated with disturbance of the intestinal wall of the upper jejunum. It is likely to be normal in the majority of patients with regional enteritis. The folic acid excretion test gives essentially similar diagnostic information. Two patients with adult coeliac disease had normal xylose excretion tests but abnormal folic acid excretions. In one patient with megaloblastic anaemia of pregnancy, the xylose excretion was abnormal when the folic acid excretion was normal. Butterworth et al. (1959) found abnormal tests in two patients out of nine. d.Xylose excretion in pregnancy, however, needs further investigation before the significance of low results in anaemia of pregnancy can be fully determined.

\section{SUMMARY}

The five-hour urinary excretion of d.xylose in 35 normal subjects aged 20-62 was found to be $7 \cdot 2$ g. (S.E. 0.27). There was a progressive diminution in excretion in older age groups so that over the age of 65 excretion values below $4.2 \mathrm{~g}$. were of little diagnostic significance.

The findings of d.xylose excretion less than $4.2 \mathrm{~g}$. in patients suspected of pancreatitis with steatorrhoea, of pernicious anaemia, or of normal values in patients suspected to be suffering from adult coeliac disease or tropical sprue should cause their diagnoses to be more carefully evaluated.

In any patient who is not pregnant, the finding of a low xylose excretion in this test should indicate involvement of the jejunum.

No particular diagnostic merit can be attached to the test in regional enteritis, ulcerative colitis, cirrhosis of the liver, or post-gastrectomy syndromes.

We are indebted to the Endowment Research Funds of the United Birmingham Hospitals for financial support, and to Miss Brenda Brooke for technical assistance.

\section{REFERENCES}

Benson, J. A., Culver, P. J., Ragland, S., Jones, C. M., Drummey, G. D., and Bougas, E. (1957). New Engl. J. Med., 256, 335.

Brien, F. S., Turner, D. A.., Watson, E. M., and Geddes, J. H. (1952). Gastroenterology, 20, 287.

Butterworth, C. E., Perez Santiago, E., Martinez-de Jesus, J., and Santini, R.' (1959). Medical Science Publication No. 5, Tropical Sprue, Washington, p. 277.

Cox, E. V., Meynell, M. J., Cooke, W. T., and Gaddie, R. (1958), Gastroenterology, 35, 390.

Crosby, W. H., and Kugler, H. W. (1957). Amer. J. dig. Dis., n.s. 2, 236.

Finlay, J. M., and Wightman, K. J. R. (1958). Ann. intern. Med., 49,1332 .

Fourman, L. P. R. (1948). Clin. Sci., 6, 289.

Gardner, F. H., and Perez Santiago, E. (1956). A.M.A. Arch. intern. Med., 98, 467.

Hele, M. P.' (1953). Biochem. J., 55, 857.

Helmer, O. M., and Fouts, P. J.' (1937). J. clin. Invest., 16, 343.

Hiatt, H. H. (i957). J. biol. Chem., 224, 851

McCance, R. A., and Madders, K. (1930). Biochem. J., 24, 795

Ota, S., and Shibata, M. (1954). Kyúshú Mem. med. Sci., $5,107$.

Roe, J.' H., and Rice, E. W. (1948). J. biol. Chem., 173, 507 .

Wyngaarden, J. B., Segal, S., and Foley, J. B. (1957). J. clin. Invest. 36, 1395 . 